\title{
METHODS FOR SANITARY SURVEILLANCE OF LIVESTOCK PRODUCTION. VII. ENZYMOIMMUNOASSAY OF STREPTOMYCIN
}

\author{
M.A. Burkin ${ }^{1}$, I.A. Gal'vidis ${ }^{1}$, G.P. Kononenko ${ }^{2}$ \\ I.I. Mechnikov Research and Development Institute for Vaccines and Sera, RAMS, Moscow 105064, Russia \\ e-mail: instmech@iitp.ru \\ 2 All-Russia Research and Development Institute of Veterinary Sanitation, Hygiene and Ecologyl, RAAS, Moscow 123022, Russia \\ e-mail: kononenkogp@mail.ru
}

Received March 3, 2012

Sum mary

The polyclonal rabbit antibodies against streptomycin conjugated with bovine serum albumin in reaction with diglycidyl ether of 1,4-butanediol presents high specificity to streptomycin and its similar structural analog — dihydrostreptomycin. In the conditions of indirect competitive enzymoimmunoassay with immobilized antigens, heterologous to immunogene on protein carrier and methods of synthesis, the limit of streptomycin detection is $0.1 \mathrm{ng} / \mathrm{ml}$. The authors consider the use of developed immunoenzyme test-systems for control of antibiotic contamination in milk and eggs with the limit of detection of $10 \mathrm{mkg} / \mathrm{kg}$ and in meat with the limit of $20 \mathrm{mkg} / \mathrm{kg}$.

Keywords: streptomycin, milk, eggs, meat, immunoassay.

Streptomycin (SM) is aminoglycoside antibiotic widely used for many years in our country and abroad for the treatment of acute infectious diseases of animals, despite its dangerous side effects such as allergic reactions, disorders of neuromuscular conduction, and ototoxicity (1 2). In modern practice, the control of SM residues in animal products is often based on enzyme-linked immunosorbent assay (ELISA). This method was implemented in several countries in the form of test systems of various types including biosensor technology (3-12). Russian researchers also have proposed a test system based on direct ELISA and the evaluation test using immunochromatography for the control of SM in milk and dairy products $(13,14)$.

The purpose of this work was obtaining specific immunoreagents based on streptomycin, optimization of conditions of the indirect competitive solid-phase immunoassay, and assessing the applicability of this test system for the control of SM residues in milk, eggs and meat.

Technique. The experiment was performed using the following chemicals: streptomycin sulfate, diglycidyl ether of 1,4butanediol, adipic acid dihydrazide, 1-ethyl-3-(3-dimethylaminopropyl) carbodiimide hydrochloride (EDCI), human transferrin (HT) ("Sigma", USA ), sodium borohydride ("Serva", Germany), dihydro-streptomycin (G.F. Gauze Research Institute of New Antibiotics, Moscow), dimethylformamide ("Fluka", Germany), bovine serum albumin (BSA), gelatin (Gel) and antispecies enzyme conjugate prepared according to the description (15) from horseradish peroxidase (EC 1.11.1.7) and donkey antiserum to rabbit immunoglobulin, sodium periodate of domestic production. ELISA was conducted on high-binding polystyrene plates ("Costar", USA) using a photometer Dynatech MR 5000 ("Dynatech", Germany).

The reaction with diglycidyl ether of 1,4-butanediol for the synthesis of conjugates of SM with BSA and Gel - BSASM(100)e, Gel-SM(10)e, Gel-SM(30)e, and Gel-SM(100)e: $6,8 \mathrm{mg}$ SM sulfate (10 umol) in $1 \mathrm{ml} 1 \% \mathrm{NaHCO}_{3}$ was added with 14 ul (10 umol) diglycidyl ether of 1,4-butanediol (10\% solution in dimethylformamide) and stirred at room temperature for 24 hours. Then, $4 \mathrm{mg}$ BSA $(0,06 \mathrm{umol})$ in $0,5 \mathrm{ml}$ of $0,05 \mathrm{M}$ carbonate-bicarbonate buffer $(\mathrm{CBB}, \mathrm{pH} 9,5)$ was added with $600 \mathrm{ul}$ of the abovementioned mixture (100-fold molar excess of hapten), and three portions of $4 \mathrm{mg}$ Gel $(0,025 \mathrm{umol})$ in $0,5 \mathrm{ml} \mathrm{CBB}-\mathrm{with}$, respectively, 25; 75, and 250 ul (10-, 30-, and 100-fold molar excesses), then stirred for 3 hours and dialyzed .

The reaction with adipic acid dihydrazide for the synthesis of SM conjugates with BSA and Gel- BSA-SM(100)h, Gel$\mathrm{SM}(10) \mathrm{h}, \mathrm{Gel-SM}(30) \mathrm{h}$, and Gel-SM(100)h: firstly, $4 \mathrm{mg} \mathrm{BSA}(0,06 \mathrm{umol})$ and $12 \mathrm{mg}$ Gel $(0,075 \mathrm{umol})$ (resp., in 0,5 and 1,5 ml water) were added with EDCI (resp., 15 and $30 \mathrm{mg}$ ), stirred for 30 minutes, and then the mixture with Gel was divided to 3 equal portions. Then, an aqueous solution of $6,8 \mathrm{mg}$ SM sulfate (10 umol) was added with 1,8 $\mathrm{mg}$ of adipic acid dihydrazide and stirred at room temperature overnight. After that, the portion with BSA was added with $600 \mathrm{ul}$ of the mixture containing the reaction product of SM and adipic acid dihydrazide (100-fold molar excess), while the portions with Gel - with, respectively, 25; 75, and 250 ul (10-, 30-, and 100-fold molar excesses), then stirred for 2 hours at room temperature and dialyzed.

The method of synthesis of conjugates HT-SM(30) and HT-SM(100) was similar to the described previously (16): 20 mg HT $(0,26$ umol $)$ in $3 \mathrm{ml}$ water was added with $17 \mathrm{mg}$ sodium periodate and stirred on a magnetic stirrer for 15 minutes. The product was dialyzed against 51 of $10 \mathrm{mM}$ acetate buffer $\left(\mathrm{pH} \mathrm{5,0)}\right.$ for 24 hours at $4{ }^{\circ} \mathrm{C}$. The resulting dialyzate was divided to 2 equal portions that were added with, respectively, 2,6 and $8,8 \mathrm{mg} \mathrm{SM}$ sulfate (30- and 100-fold molar excesses) in $1 \mathrm{ml} \mathrm{CBB}$, and incubated with stirring for 2 hours. Then the reaction mixtures were added with 100 ul aqueous solution of sodium borohydride with a concentration of $2 \mathrm{mg} / \mathrm{ml}$ and stirred for 2 hours

The reaction products were dialyzed against two changes of water (each of 5 1), after which the dialysate was added with an equal volume of glycerol and stored at $-10 \ldots-15{ }^{\circ} \mathrm{C}$. Gray rabbits-males $(2-3 \mathrm{~kg})$ were immunized with conjugates BSA-SM(100)e, BSA-SM $(100) h$, and HT-SM(100). At the $1^{\text {st }}$ and $2^{\text {nd }}$ injections, the animals received 200 ug of immunogen in Freund's complete adjuvant subcutaneously in 10-15 points of the back, at each of all subsequent injections - 100 ug immunogen in physiological solution. In 7 days after each next injection administered with intervals of 1 month, the blood samples were obtained from the marginal ear vein; the blood serum was separated, added with an equal volume of glycerol and stored at $-10 \ldots-15{ }^{\circ} \mathrm{C}$. Testing the sera's specificity and the conjugates used as solid-phase antigens, as well as ELISA were performed similarly to those described previously (17).

The tested samples of cow milk, chicken eggs and meat (beef) were purchased from the market network of Moscow. Milk and homogenized contents of eggs (yolk and white) before the analysis were diluted in PBS-T 100-fold. Meat (beef) was thoroughly 
homogenized, the samples were put in graduated test tubes and added with $0,15 \mathrm{M}$ phosphate-buffered saline (composition: $0,01 \mathrm{M}$ $\mathrm{Na}_{2} \mathrm{HPO}_{4}, 0,14 \mathrm{M} \mathrm{NaCl}$, and $0,05 \%$ Tween 20 (PBS-T); $\mathrm{pH} 7,5$ ) at a rate of $1 \mathrm{~g}$ per $5 \mathrm{ml}$, which after intense shaking was left for 24 hours at $4{ }^{\circ} \mathrm{C}$. Then, these test tubes were incubated at $60{ }^{\circ} \mathrm{C}$ for $10 \mathrm{~min}$ and centrifuged. A portion of the supernatant was diluted with PBS-T 40-fold and tested by ELISA.

Metrological characteristics of the applied techniques were evaluated by measuring the amount of SM intentionally introduced in tested milk, eggs and meat.

Results. According to the scientific literature, there are several ways to synthesize immunogens necessary for production of antibodies to SM, and each of them has become the basis of test systems for the control of livestock products. In 1993, it was reported about obtaining the antibodies to protein conjugates of SM modified by carboxymethyloxime for aldehyde group (3, 4, 8, 12, 13). Later, this was performed using the reaction of SM with glutaraldehyde and carbodiimide condensation (9), binding of methylamino group with cyanuric chloride $(11,14)$, and modification of SM by adipic acid dihydrazide $(6,7,10)$.

Protein conjugates synthesized through the reaction of SM methylamino group with another bifunctional reagent -diglycidyl ether of 1,4-butanediol - were used as trapping immunoreagents and immobilized antigens, when they showed high reactivity (5, 9, 11).

In this research, the rabbits were immunized with BSA-based immunogens synthesized by different methods, and SM conjugate with pre-oxidized human transferrin derived through reductive amination. Previously, a similar immunogen was used to obtain antibodies to neomycin (16).

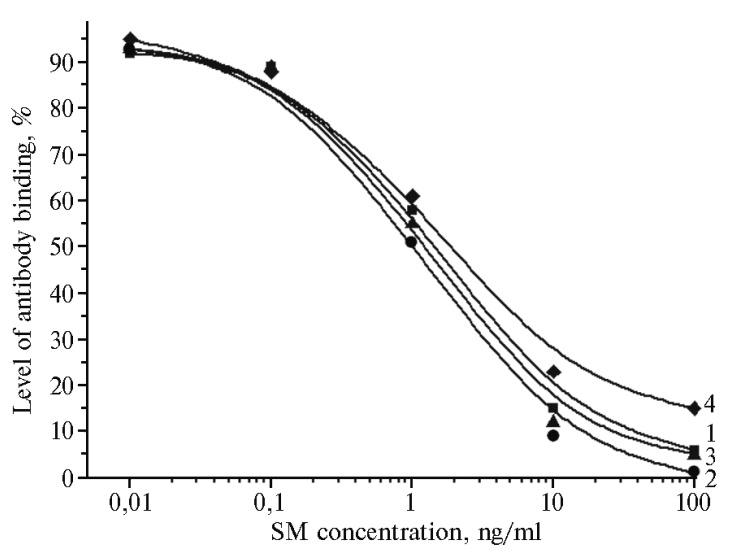

Fig. 1. Degree of binding of antibodies to BSA-SM(100)e from the $2^{\text {nd }}-5^{\text {th }}$ blood samples $(1-4)$ with a solid-phase antigen GELSM(30)g at the presence of SM in PBS-T buffer: BSA, Gel, SM, PBS-T - resp., bovine serum albumin, gelatin, streptomycin, phosphate-buffered saline with Tween 20.(ELISA)

Conjugates of SM with BSA and Gel were synthesized using the modified simplified procedures and two bifunctional reagents - diglycidyl ether of 1,4-butanediol and adipic acid dihydrazide. In contrast to the technique described by R.A. Abuknesha et al. (11), the reaction of SM-sulphate with diglycidyl ether of1,4-butandiol was carried out in an aqueous medium without the addition of dimethyl sulfoxide, and the product wasn't purified by extraction into chloroform. The reaction mixture was incubated with the protein solutions for 3 hours instead of 16 hours. During the conjugation of SM with adipic acid dihydrazide, at the first stage instead of 90 minutes of boiling the mixture of substances in aqueous methanol and isolating the crystallized reaction product as described $(6,10)$, they were just stirred at room temperature for 2 hours. Carboxyl groups of proteins were activated with one reagent (EDCI) instead of two (N-hydroxysuccinimide and EDCI) in sodium acetate solution. At the final stage, the reaction with proteins wasn conducted 2 hours at room temperature instead of overnight.

Since it wasn't possible to confirm spectrophotometrically and evaluate the hapten load of conjugates due to the absence of SM absorption in UV region, as immunogens there served conjugates of BSA and HT with the maximum excess of hapten in the reaction - BSA-SM(100)h, BSA-SM(100)e, and HT-SM(100). The other synthesized conjugates were used as a solid phase antigens.

Antisera to BSA-SM(100)h and HT-SM(100) showed active interaction with all immobilized conjugates, but the presence of even $1 \mathrm{ug} / \mathrm{ml}$ of free SM didn't inhibit the binding. On the contrary, immunization with BSA-SM(100)e provided already in the $1^{\text {st }}$ blood sample the antiserum containing antibodies capable to recognize free SM (Fig. 1).

The $3^{\text {rd }}$ injection of the immunogen to the animals ( $2^{\text {nd }}$ blood sample) resulted in the antibodies with working titer 1:20001:3000 allowing determination of SM in solutions with concentration up to $0,1 \mathrm{ng} / \mathrm{ml}$. However, continuation of immunization procedures to the $5^{\text {th }}$ blood sample was accompanied by the decline in working titer up to 1:500 with insignificant change of test sensitivity (Table 1).

1. Interaction of antibodies to BSA-SM(100)e in sera from the $2^{\text {nd }}-5^{\text {th }}$ blood samples with different immobilized antigens at the presence of SM (ELISA).

\begin{tabular}{|c|c|c|c|c|}
\hline \multirow{3}{*}{ Blood sample } & \multicolumn{4}{|c|}{ Immobilized antigen } \\
\hline & \multicolumn{2}{|c|}{ Gel-SM(30)h } & \multicolumn{2}{|c|}{ HT-SM(100) } \\
\hline & working titer & $\mathrm{IC}_{50}$ & working titer & $\mathrm{IC}_{50}$ \\
\hline $2^{\text {nd }}$ & $1: 2000$ & 1,4 & $1: 3000$ & 1,1 \\
\hline $3^{\text {rd }}$ & $1: 1000$ & 1,0 & $1: 1000$ & 0,9 \\
\hline $4^{\text {th }}$ & $1: 800$ & 1,2 & $1: 800$ & 0,9 \\
\hline $5^{\text {th }}$ & $1: 500$ & 1,9 & $1: 500$ & 0,9 \\
\hline
\end{tabular}

All the synthesized conjugates showed immunoreactivity when used as solid-phase antigens, though test sensitivity was slightly higher for Gel-SM(30)h and HT-SM(100) conjugates heterologous to the immunogen.

Evaluation of antibodies' specificity has shown that cross-reactivity to dihydro-SM (the closest structural analog of SM) was twice higher, or $200 \%$. The comparable level of cross-reactivity to dihydro-SM was described in polyclonal antibodies to conjugates of SM with albumin synthesized by different methods: for the synthesis through methylamino group with cyanuric chloride - $75 \%$ (11), for adipic acid dihydrazide - 80\% (10) and 103\% (7), in the case of carboxymethyloxime binding for aldehyde group - $85,7 \%$ (3), $118 \%$ (12), and 149\% (4). In this research, the derived antibodies expressed unusually high recognition of dihydro-SM possibly due to peculiarities of their hapten orientation relative to BSA in the immunogen, which resulted from specific conditions of conjugation with diglycidyl ether of 1,4-butanediol. For other aminoglycosides (neomycin, gentamicin, sisomycin, kanamycin, tobramycin, amikacin, and apramycin), there wasn't any inhibition of binding even at a concentration of $10,000 \mathrm{ng} / \mathrm{ml}$. 


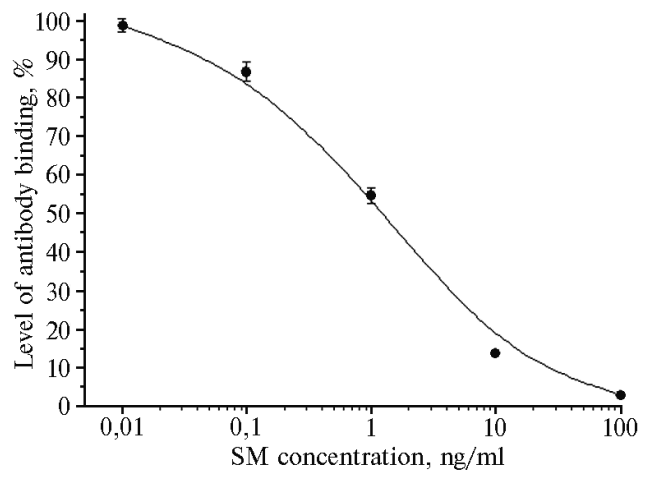

Fig. 2. Calibration chart for ELISA of SM $(n=4)$ using antiserum to BSA-SM(100)e from the $4^{\text {th }}$ blood sample and immobilized antigen GEL-SM(30)h. SM, BSA, Gel - streptomycin, bovine serum albumin, gelatin.
ELISA calibration curves of SM in variants with antiserum from the $4^{\text {th }}$ blood sample and solid-phase antigens Gel-SM(30)h and HT-SM(100) didn't differ. Analytical characteristics $(n=4)$ measured in the laboratory under conditions of intermediate precision daily or at an interval of 1-2 days, had a relative standard deviation of less than 0,05 , which indicated stable functioning of the test-system under normal fluctuations of external factors (Fig. 2).

Sensitivity of detection of SM $0,1 \mathrm{ng} / \mathrm{ml}$ was comparable to that reported by H. Watanabe et al. (8) and exceeded the level mentioned in all other reports on direct and indirect ELISA, immunochromatographic and immunoassays based on optical biosensors. For dihydro-SM, a close limit of detection was observed (considering that specificity of antibodies to this antibiotic was only twice higher).

Specificity and high sensitivity to SM, as well as stable functioning of the developed test systems allowed exploring the possibility of their use for the control of animal products - milk, eggs, and meat.

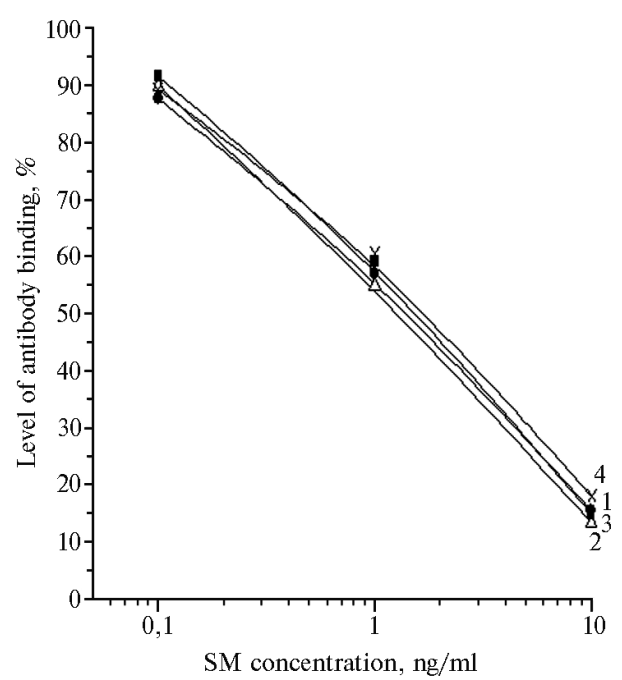

Fig. 3. Calibration charts for ELISA of SM with antiserum to BSA-SM(100)e from the $4^{\text {th }}$ blood sample and a solid-phase antigen GEL-SM(30)h in PBS-T buffer (1), in milk 100-fold diluted with PBS-T (2), in a homogenized egg 100-fold diluted with PBS-T (3), and in meat extract 40-fold diluted with PBS-T (4). BSA, Gel, SM, PBS-T - resp., bovine serum albumin, gelatin, streptomycin, phosphate-buffered saline with Teen 20.
Calibration graphs for PBS-T and milk diluted with PBS-T 100-fold (Fig. 3), were almost similar and provided the detection of SM at concentrations ranging from 0,1 to $10 \mathrm{ng} / \mathrm{ml}$. This method allows examining tens of samples for SM content from 10 to $1000 \mathrm{ug} / \mathrm{kg}$ during 3,5-4,0 h (current regulation permits not more than 200 $\mathrm{ug} / \mathrm{kg}$ or $0,2 \mathrm{mg} / \mathrm{kg})(18)$.

For egg homogenates diluted with PBS-T 100-fold, calibration graph also didn't change (Fig. 3). Testing SM content in 37 samples of the product obtained from 28 poultry farms revealed the absence of SM content in the samples above 10 $\mathrm{ug} / \mathrm{kg}$.

Testing the extracts of beef homogenized with PBS-T and then diluted 40fold, calibration curves did not differ from those of the buffer solution (Fig. 3). In this variant, the upper and lower detection limit were, respectively, 20 and $2000 \mathrm{ug} / \mathrm{kg}$. The current regulations permit the presence of SM in meat and liver of all kinds of slaughtered animals $(500 \mathrm{ug} / \mathrm{kg})$, and kidney $(1000 \mathrm{ug} / \mathrm{kg})(18)$, which is within the achieved limit of SM detection.

Evaluation of metrological characteristics of the applied methods showed quite satisfactory convergence of results and accuracy of determination (Table 2).

2. Results of testing the samples of milk, eggs, and meat containing SM introduced at different quantities, by means of ELISA with antiserum to BSA-SM(100)e from the $4^{\text {th }}$ blood sample with immobilized antigen $\operatorname{Gel-SM}(30) h(n=4)$

\begin{tabular}{|c|c|c|c|}
\hline Sample & $\mathrm{SM}$ introduced, $\mathrm{ng} / \mathrm{g}$ & SM detected, ng/g & $\begin{array}{l}\text { Accuracy of determi- } \\
\text { nation, } \%\end{array}$ \\
\hline \multirow{2}{*}{ Milk } & 100 & $100 \pm 16$ & 100 \\
\hline & 200 & $212 \pm 36$ & 106 \\
\hline \multirow[t]{3}{*}{ Eggs } & 250 & $288 \pm 8$ & 115 \\
\hline & 500 & $637 \pm 6$ & 127 \\
\hline & 1000 & $1157 \pm 130$ & 116 \\
\hline Meat & 500 & $452 \pm 40$ & 90 \\
\hline
\end{tabular}

The coefficients of variation (or relative standard deviations) averaged 12,5\%, which indicated that the analytical result wasn't significantly affected by changes in conditions. The correctness of performed measurements was considered from the value of deviation of determined SM quantities from the nominals in relative expression averaged 12,3\% over the variants of the experiment.

Thus, polyclonal rabbit antibodies to streptomycin conjugated to bovine serum albumin through the reaction with diglycidyl ether of 1,4-butanediol, showed high specificity to streptomycin (SM) and its closest structural analogue dihydro-streptomycin. In the conditions of indirect competitive enzyme immunoassay (ELISA) with the immobilized antigens heterologous to immunogen for protein carrier, and the applied methods of synthesis, the limit of detection of streptomycin was $0,1 \mathrm{ng} / \mathrm{ml}$.

The possibility of determining SM in animal products by means of simple approaches of sample preparation and indirect ELISA allows to develop the appropriate techniques and test systems for practical use. The authors' experience of successful use of simple two-stage techniques with extraction and indirect ELISA detecting a wide range of antimicrobial medications (antibiotics of the tetracycline group, bacitracin, gentamicin, ciprofloxacin and its analogues, sulfadimidine, chloramphenicol, streptomycin) suggests the possibility of creating a unified methodological basis for monitoring of residual antibiotic content in animal products, as well as its implementation in the practice of testing laboratories. 


\section{REFERENCES}

1. Klenova I.F. and Yaremenko N.A., Veterinarnye preparaty v Rossii. Spravochnik (Reference Book of Veterinary Medications in Russia), Moscow, 2001.

2. Spravochnik veterinarnykh preparatov (A Reference Book of Veterinary Medications), Pankovets E.A., Ed., Minsk, 1996.

3. Dietrich R., Schnappinger P., Usleber E., and Terplan G., Entwicklung und Anwendung von Monoklonalen Antikorpern gegen Streptomycin, Milchwissenschaft, 1993, vol. 48, p. 588.

4. Schnappinger P., Usleber E., Martlbauer E., and Terplan G., Enzyme Immunoassay for the Detection of Streptomycin and Dihydrostreptomycin in Milk, Food Agric. Immunol., 1993, vol. 5, pp. 67-71.

5. Verheijen R., Osswald I.K., Dietrich R., and Haasnoot W., Development of a One Step Strip Test for the Detection of (Dihydro)Streptomycin Residues in Raw Milk, Food Agric. Immunol., 2000, vol. 12, no. 1, pp. 31-40.

6. Baxter G.A., Ferguson J.P., O’Connor M.C., and Elliott C.T., Detection of Streptomycin Residues in Whole Milk Using an Optical Immunobiosensor, J. Agric. Food Chem., 2001, vol. 49, pp. 3204-3207.

7. Ferguson J.P., Baxter G.A., McEvoy J.D.G., et al., Detection of Streptomycin and Dihydrostreptomycin Residues in Milk, Honey and Meat Samples Using an Optical Biosensor, Analyst, 2002, vol. 127, pp. 951-956.

8. Watanabe H., Statake A., Kido Y., and Tsuji A., Monoclonal-Based Enzyme-Linked Immunosorbent Assay and Immunochromatographic Rapid Assay for Dihydrostreptomycin in Milk, Analyt. Chim. Acta, 2002, vol. 472, no. 1-2, pp. 45-53.

9. Haasnoot W., Loomans E., Cazemier G., et al., Direct versus Competitive Biosensor Immunoassays for the Detection of (Dihydro)Streptomycin Residues in Milk, Food Agric. Immunol., 2002, vol. 14, no. 1, pp. 15-27.

10. Faridah S., Zamri I., Tan C.S., et al., Development of Direct Competitive Enzyme Immunoassay Kit for the Detection of Streptomycin Residues in Chicken Meat and Feed, J. Trop. Agric. Fd. Sc., 2004, vol. 32, no. 2, pp. 179-186.

11. Abuknesha R.A. and Luk C., Enzyme Immunoassays for the Analysis of Streptomycin in Milk, Serum and Water: Development and Assessment of a Polyclonal Antiserum and Assay Procedures Using Novel Streptomycin Derivatives, Analyst, 2005, vol. 130, pp. 964-970.

12. Wu J.X., Zhang S.T., and Zhou X.P., Monoclonal Antibody-Based ELISA and Colloidal Gold-Based Immunochromatographic Assay for Streptomycin Residue Detection in Milk and Swine Urine, J. Zhejiang Univ-Sci (Biomed \& Biotechnol), 2010, vol. 11, no. 1, pp. 52-60.

13. Samsonova J.V., Bashkurov M.L., Ivanova N.L., Rubtsova M.Y., and Egorov A.M., ELISA of Streptomycin in Buffer and Milk: Effect of Reagents' Structure and Analysis Format on Assay Performance, Food Agric. Immunol., 2005, vol. 16, no. 1, pp. 47-57.

14. Byzova N.A., Zvereva E.A., Zherdev A.V., Eremin S.A., Sveshnikov P.G., and Dzantiev B.B., Pretreatment-Free Immunochromatographic Assay for the Detection of Streptomycin and Its Application to the Control of Milk and Dairy Products, Analyt. Chim. Acta, 2011, vol. 701, pp. 209-217.

15. Nakane P.K. and Kawaoi A., Peroxidase-Labeled Antibody. A New Method of Conjugation, J. Histochem. Cytochem., 1974, vol. 22, no. 2, pp. 1084-1091.

16. Burkin M.A. and Galvidis I.A.,Development and Application of Indirect Competitive Enzyme Immunoassay for Detection of Neomycin in Milk, Prikladnaya biokhimiya i mikrobiologiya, 2011, vol. 47, no. 3, pp. 355-361.

17. Burkin A.A., Kononenko G.P., and Burkin M.A., Methods of Sanitary Control of Livestock Products. I. Enzymoimmunoassay (ELISA) of Tetracyclines, , S.-kh. biol., 2010, vol. 4, pp. 110-117.

18. Sanitary Regulations and Standards SanPiN 2.3.2.1078-01 Hygienic Requirements of Safety and Nutritional Value of Food Products 